\title{
Cigarette smoke exposure impairs reverse cholesterol transport which can be minimized by treatment of hydrogen-saturated saline
}

\author{
Chuanlong Zong ${ }^{1 * \dagger}$, Guohua Song ${ }^{1+}$, Shutong Yao ${ }^{1}$, Shoudong Guo ${ }^{1}$, Yang Yu', Nana Yang ${ }^{1}$, Zheng Guo ${ }^{2}$
} and Shucun Qin ${ }^{*}$

\begin{abstract}
Background: Cigarette smoke (CS) exposure impaired plasma lipid profiles by modification of apolipoproteins. Hydrogen $\left(\mathrm{H}_{2}\right)$ has been proved effective on reducing oxidative stress or improving HDL functionalities in animal models or metabolic syndrome volunteers. This study was undertaken to explore the effects of CS exposure on reverse cholesterol transport (RCT) and the antioxidative effects of $\mathrm{H}_{2}$ treatment against CS exposure in mice transgenic for human cholesteryl ester transfer protein (CETP).
\end{abstract}

Methods: $\left[{ }^{3} \mathrm{H}\right]$-cholesterol-laden macrophages were injected intraperitoneally into mice, and the samples of blood, bile, liver, and feces were collected for radioactivity determination to evaluate $\mathrm{RCT}$. $\left.{ }^{3} \mathrm{H}\right]$-cholesterol-laden macrophages were incubated with HDL isolated from different groups of mice, and the samples of cell medium supernatants were collected for evaluating the HDL functionality to elicit cholesterol efflux.

Results: CS exposure significantly decreased plasma HDL cholesterol level (HDL-C) by $22 \%$ and increased LDL cholesterol level (LDL-C) by $21 \%$ compared with the control group $(p<0.05, p<0.01)$, while $\mathrm{H}_{2}$ treatment significantly improved the CS-impaired levels of TC, LDL-C and HDL-C by 10, 27 and $31 \%$, respectively, compared with the CS group $(p<0.05, p<0.01$ and $p<0.05)$. Besides, CS exposure significantly decreased $\left[{ }^{3} H\right]$ tracer concentrations in liver, bile and feces by 17,35 and $48 \%$, respectively, compared with the control group ( $p<0.05$ for liver and feces), while $\mathrm{H}_{2}$ treatment significantly improved them by $21,72 \%$ and $89 \%$, respectively, compared with the CS group (all $p<0.05$ ). Furthermore, CS exposure significantly decreased the HDL functionality to elicit cholesterol efflux by $26 \%(p<0.05)$, while $\mathrm{H}_{2}$ treatment also improved it by $32 \%(p<0.05)$. We did not find any significant alterations in protein expressions of RCT involved genes.

Conclusions: These findings provided direct evidence supporting the notion that CS exposure in vivo impairs plasma lipid profiles, HDL functionalities and macrophage-to-feces RCT pathway in CETP transgenic mice, all of which can be minimized by treatment of $\mathrm{H}_{2}$-saturated saline.

Keywords: Cigarette smoke exposure, Hydrogen, Reverse cholesterol transport, High-density lipoprotein, Human CETP transgenic mice

\footnotetext{
* Correspondence: chlzong@tsmc.edu.cn; shucunqin@hotmail.com

${ }^{\dagger}$ Equal contributors

${ }^{1}$ Key Laboratory of Atherosclerosis in Universities of Shandong Province, Institute of Atherosclerosis, Taishan Medical University, 2\# Yingsheng East Road, Taian, Shandong 271000, PR China

Full list of author information is available at the end of the article
}

C Biomed Central

(c) 2015 Zong et al. Open Access This article is distributed under the terms of the Creative Commons Attribution 4.0 International License (http://creativecommons.org/licenses/by/4.0/), which permits unrestricted use, distribution, and reproduction in any medium, provided you give appropriate credit to the original author(s) and the source, provide a link to the Creative Commons license, and indicate if changes were made. The Creative Commons Public Domain Dedication waiver (http://creativecommons.org/publicdomain/zero/1.0/) applies to the data made available in this article, unless otherwise stated. 


\section{Background}

Reverse cholesterol transport (RCT) is generally defined as cholesterol efflux from peripheral cells to plasma HDL uptaked by hepatocytes for utilization, direct secretion into bile and feces disposal $[1,2]$. Therefore, the intact HDL functionalities have been believed to be atheroprotective in atherosclerosis development [3]. Cholesteryl ester transfer protein (CETP) facilitates removal of cholesterol ester from plasma HDL in exchange for triglycerides from low-density lipoproteins or very low-density lipoproteins (LDL or VLDL) [4, 5]. Since wild C57BL/6 J mouse lacks CETP gene necessary for simulating human lipid profiles [6], human CETP transgenic heterozygous mice with a C57BL/6J background were used in the present study.

Both animal and human studies have demonstrated that cigarette smoke (CS) exposure significantly increased levels of plasma total cholesterol (TC), total triglyceride (TG), LDL-cholesterol (LDL-C), but decreased the level of HDLCholesterol (HDL-C) [7-9]. A few in vitro studies revealed that CS exposure promoted the modification of lysine amino residue on HDL which would thus lose the functionality to stimulate cholesterol efflux from macrophages $[10,11]$. On the other hand, our previous studies demonstrated that $\mathrm{H}_{2}$-rich water or $\mathrm{H}_{2}$-saturated saline decreased aortic atherosclerosis, improved HDL functionalities, and reduced the oxidative stress in animal models or metabolic syndrome volunteers [12-14]. Based on these findings, we proposed that CS exposure in vivo impairs HDL functionalities or RCT pathway in CETP transgenic mice, and that the impairment by CS exposure could be minimized by treatment of $\mathrm{H}_{2}$-saturated saline.

\section{Methods}

\section{Materials}

Acetylated low density lipoprotein particles (ac-LDL) were prepared from $48 \mathrm{~mL}$ of fresh blood from a healthy volunteer by sequential ultracentrifugation $[15]$. [ $\left.{ }^{3} \mathrm{H}\right]$-labeledcholesterol was purchased from PerkinElmer (Waltham, MA, USA). Enzymatic assay kits for plasma lipid determinations were purchased from BioSino (Beijing, China). Kit for measuring formation of thiobarbituric acid reactive substances (TBARS) was from Jiancheng Biochemistry (Najing, China). All antibodies were purchased from Abcam (Cambridge, MA, USA). Commercial Taishan cigarettes (11 mg of tar,1.1 mg of nicotine,12 mg of carbon monoxide, Shandong, China) are used in the present study.

\section{Animals and grouping}

Mice of human CETP transgenic strain with a C57BL/6J background were presented by Dr. Xiancheng Jiang (Department of Anatomy and Cell Biology, SUNY Downstate Medical Center). All CETP transgenic mice were offspring littermates of CETP heterozygous mice. Seventy-two male CETP transgenic mice, 10 weeks old, fed a chow diet (Keaoxieli Co. LTD, Beijing, China) and water ad libitum, were housed in a temperature and humidity controlled room with a 12/12 h light-dark cycle. Mice were exposed to either room air or CS at five cigarettes/d and $5 \mathrm{~d} /$ wk for 12 weeks. During the last four weeks the mice were intraperitoneally injected with $\mathrm{H}_{2}$-saturated saline or vehicle (saline) once daily. All animal experiments were conducted in accordance with the Guidelines for Care and Use of Laboratory Animals of Taishan Medical University, and this study was approved by the Laboratory Animals' Ethical Committee of Taishan Medical University.

The animals were randomly divided into the control group, the $\mathrm{H}_{2}$ group $\left(\mathrm{H}_{2}\right.$-saturated saline treated, $5 \mathrm{~mL} / \mathrm{kg} / \mathrm{d}$ ), the CS group (CS exposed) and the $\mathrm{H}_{2}+$ $\mathrm{CS}$ group $\left(\mathrm{H}_{2}\right.$-saturated saline treated plus $\mathrm{CS}$ exposed) $(n=18)$. In addition, a group of eight C57BL/6J mice were added in the experiment of plasma lipid determination to verify the phenotype of CETP transgenic mice.

\section{Equipment for CS exposure}

Cages for CS exposure were re-designed according to Escolar et al. [16]. Briefly, the cages $(42.5 \times 26.6 \times 19 \mathrm{~cm})$ were equipped with a disposable filter cover having 15 $10-\mathrm{mm}$ holes that enabled inside air to be flown out of the cages and thus to be continuously renewed. CS was produced by cigarette burning and introduced into the chamber with airflow generated by a $50 \mathrm{~mL}$ medical syringe manipulated by a researcher, at a rate of $125 \mathrm{~mL} / \mathrm{min}$. Five cigarettes were smoked one by one within $20 \mathrm{~min}$. A rodent ventilator (Ugo Basile, Shanghai, China) was used to provide fresh room air for dilution (1:8) of smoke stream.

\section{Preparation of $\mathrm{H}_{2}$-saturated saline}

$\mathrm{H}_{2}$ was produced with a self-designed apparatus and immediately dissolved into normal sterile saline to supersaturated concentration for $2 \mathrm{~h}$ under high pressure (0.6 MPa). $\mathrm{H}_{2}$-saturated saline, stored under atmospheric pressure and $4{ }^{\circ} \mathrm{C}$, was freshly prepared every 3 days to ensure a constant $\mathrm{H}_{2}$ concentration of not less than $0.6 \mathrm{mM}$.

\section{Preparation of $\left[{ }^{3} \mathrm{H}\right]$-cholesterol-laden macrophages}

Briefly, as described by $\mathrm{Yu}$ et al. [17], Raw264.7 cells were incubated with $\left[{ }^{3} \mathrm{H}\right]$-cholesterol $(5 \mu \mathrm{Ci} / \mathrm{mL})$ and ac-LDL $(100 \mu \mathrm{g} / \mathrm{mL})$ for $48 \mathrm{~h}$, and were then harvested at $1.0 \times 10^{6}$ cells $/ \mathrm{mL}$ for intraperitoneal injection into mice. The ratio of the intracellular $\left[{ }^{3} \mathrm{H}\right]$-cholesterol radioactivity to the total $\left[{ }^{3} \mathrm{H}\right]$-cholesterol radioactivity was more than $95 \%$, which indicated the harvested macrophages had already uptaken $95 \%$ of the total $\left[{ }^{3} \mathrm{H}\right]$-cholesterol and thus were in good condition. 
RCT assay by $\left[{ }^{3} \mathrm{H}\right]$-labeled-cholesterol tracing

After CS exposure or $\mathrm{H}_{2}$-saturated saline treatment, nine mice from each group were injected intraperitoneally with $0.5 \mathrm{~mL}$ of $\left[{ }^{3} \mathrm{H}\right]$-cholesterol-laden macrophage suspension. At $0,6,12$ and $24 \mathrm{~h}$ after injection, blood was collected from the retro-orbital sinus with heparinized capillary tubes without dietary exposure for $12 \mathrm{~h}$. The mice were then anesthetized with aether and sacrificed at $24 \mathrm{~h}$ after injection. Samples of bile, liver, and feces were collected, measured or weighed, and stored at $-80{ }^{\circ} \mathrm{C}$ for radioactivity determination $(n=9)$. Plasma samples were isolated from blood by centrifugation for liquid scintillation counting.

\section{Cholesterol efflux from macrophages}

The cholesterol efflux experiments were performed according to Smith et al. [18]. HDL was isolated from each group of mice by sequential ultracentrifugation. Raw264.7 macrophages at $50 \%$ confluence were co-cultured with acLDL $(100 \mu \mathrm{g} / \mathrm{mL})$ containing $\left[{ }^{3} \mathrm{H}\right]$-cholesterol $(1 \mu \mathrm{Ci} / \mathrm{mL})$ in RGGB (RPMI 1640 supplemented with $50 \mathrm{mM}$ glucose, $2 \mathrm{mM}$ glutamine and $0.1 \% \mathrm{BSA}$ ) for $30 \mathrm{~min}$. The macrophages were washed with PBS containing $0.1 \%$ BSA, equilibrated with RGGB for $24 \mathrm{~h}$, and cultured for $16 \mathrm{~h}$ in the presence of $300 \mu \mathrm{M}$ dibutyryl cyclic AMP (dBcAMP). The culture medium was then replaced with RGGB containing $200 \mu \mathrm{g} / \mathrm{mL}$ of HDL isolated from each group of mice. The medium supernatants were collected for radioactivity determination after $12 \mathrm{~h}$ of incubation. The macrophages were washed and dissolved in $0.4 \mathrm{~mL}$ of $0.1 \mathrm{M}$ sodium hydroxide, and lysate radioactivity was measured. The percentage of cholesterol efflux could be calculated by dividing the supernatant-derived radioactivity by the sum of the supernatant-derived radioactivity and the intracellular macrophage radioactivity $(n=6)$.

\section{LDL oxidation determination}

In the presence or absence of the HDL $(200 \mu \mathrm{g} / \mathrm{mL})$ isolated from each group of mice, LDL $(100 \mu \mathrm{g} / \mathrm{mL})$ isolated from a volunteer was incubated with freshly prepared copper sulfate $(10 \mu \mathrm{mol} / \mathrm{L})$ at $37^{\circ} \mathrm{C}$ for $2 \mathrm{~h}$. The extent of LDL oxidation was evaluated by measuring formation of TBARS $(n=6)$ [19].

\section{Preparation of mice peritoneal macrophages}

Nine mice from each group were sacrificed and intraperitoneally injected each with $5 \mathrm{~mL}$ of sterile PBS, massaging gently the abdomen for $5 \mathrm{~min}$. PBS was then drawn out and centrifugated at $1500 \mathrm{rpm}$ for $10 \mathrm{~min}$. The cells were collected and frozen at $-80^{\circ} \mathrm{C}$ for Western blot.

\section{Real-time PCR}

Cellular RNA was extracted with TRIZOL Reagent (Invitrogen, USA). cDNA was synthesized using Reverse Transcriptase (TianGen Biotech, China). Real-time PCR was performed using the SYBR-green PCR master mix kit (TianGen Biotech, China). The data were analyzed by using Rotor-gene $\mathrm{Q}$ software (ver. 1.7). Relative mRNA levels were calculated by the $2^{-\mathrm{DDCt}}$ method $(n=6)$. All primers used in this study were listed in Table 1.

\section{Western blot}

Tissue proteins were separated by sodium dodecyl sulfate polyacrylamide gel electrophoresis (SDS-PAGE), and the proteins were transferred onto polyvinylidene fluoride (PVDF) membrane. Relative expression levels of SRBI, ABCG5, CYP7A1, LDLR and ABCA1/G1 were calculated with reference to $\beta$-actin $(n=5$ for CYP7A1 and ABCG5, $n=3$ for others). All protein bands were quantified using Image-Pro Plus software (ver. 6.0).

\section{Statistical analysis}

All results were expressed as mean \pm standard deviation (S.D). To compare the means between groups, One-way

Table 1 Primers used for real-time PCR

\begin{tabular}{|c|c|c|}
\hline Gene & Primer & Sequence $\left(5^{\prime}-3^{\prime}\right)$ \\
\hline \multirow[t]{2}{*}{ PPARY } & sense & GCAGCTACTGCATGTGATCAAGA \\
\hline & Anti-sense & GTCAGCGGGTGGGACTTTC \\
\hline \multirow[t]{2}{*}{$\mathrm{ABCA} 1$} & sense & CGTTTCCGGGAAGTGTCCTA \\
\hline & Anti-sense & GCTAGAGATGACAAGGAGGATGGA \\
\hline \multirow[t]{2}{*}{ ABCG1 } & sense & GGGAAGTTGATAAAGGATGT \\
\hline & Anti-sense & GATTCGGGCTATGTATGG \\
\hline \multirow[t]{2}{*}{ SR-BI } & sense & ATCTGGTGGACAAATGGAA \\
\hline & Anti-sense & GAAGCGATACGTGGGAAT \\
\hline \multirow[t]{2}{*}{ apoA-I } & sense & GGCACGTATGGCAGCAAGAT \\
\hline & Anti-sense & CCCAGAAGTCCCGAGTCAAT \\
\hline \multirow[t]{2}{*}{ ABCG5 } & sense & AGCGTCAGCAACCGTGTC \\
\hline & Anti-sense & AGCAGCGTGGTCTTCCCT \\
\hline \multirow[t]{2}{*}{ ABCG8 } & sense & TTAAGCCACTCCCAATACA \\
\hline & Anti-sense & GTTGCTCCAAGAATAAATGA \\
\hline \multirow[t]{2}{*}{ ABCB11 } & sense & CAAATAAGGTTGTGGGTAA \\
\hline & Anti-sense & AGGACTGACAGCGAGAAT \\
\hline \multirow[t]{2}{*}{ ABCB4 } & sense & CCCCACAGAGGGTAAGAT \\
\hline & Anti-sense & CCAACCAGGGTGTCAAAT \\
\hline \multirow[t]{2}{*}{ LXRa } & sense & TITGAGCAGCGTCCATTC \\
\hline & Anti-sense & GCAGTCAGTGAGCCTTCG \\
\hline \multirow[t]{2}{*}{ HMGR } & sense & TGTTCACGCTCATAGTCGC \\
\hline & Anti-sense & CTCCGCTGTGCTGTTCTG \\
\hline \multirow[t]{2}{*}{ LDLR } & sense & GCCCAAGTCGCCATTCTC \\
\hline & Anti-sense & GCCTGAGGTCCCATCCAA \\
\hline \multirow[t]{2}{*}{ CYP7A1 } & sense & TGGGCATCTCAAGCAAACAC \\
\hline & Anti-sense & TCATTGCTTCAGGGCTCCTG \\
\hline
\end{tabular}


analysis of variance test (ANOVA) was performed. Probability values less than 0.05 were considered significant.

\section{Results}

Neither CS exposure nor $\mathrm{H}_{2}$ treatment affects mice body weights

After twelve weeks of CS exposure and four weeks of $\mathrm{H}_{2}$ treatment, we compared the data of body weight between different groups at week 12, but did not find any remarkable differences between the control and the CS group, or between the CS and the $\mathrm{H}_{2}+\mathrm{CS}$ group (Table 2).

\section{CS exposure impairs plasma lipid profiles whereas $\mathrm{H}_{2}$ treatment improves}

To ensure that model making of CETP transgenic mice was trustworthy, we determined the plasma lipid profiles of a group of the eight C57BL/6 J mice, and found that they were significantly different from those of the control group of CETP transgenic mice $(p<0.01)$. We also found that CS exposure significantly decreased plasma HDL cholesterol level (HDL-C) by $22 \%$ and increased LDL cholesterol level (LDL-C) by $21 \%$ compared with the control group ( $p<0.05, p<0.01$, respectively), while $\mathrm{H}_{2}$ treatment significantly improved the CS-impaired levels of TC, LDL$\mathrm{C}$ and HDL-C by $10 \%, 27 \%$ and $31 \%$, respectively, compared with the CS group $(p<0.05, p<0.01$ and $p<0.05$, respectively) (Fig. 1).

\section{CS exposure impairs RCT pathway which can be minimized by $\mathrm{H}_{2}$ treatment}

A classic $\left[{ }^{3} \mathrm{H}\right]$-labeled-cholesterol tracing assay was employed to evaluate the effects of $\mathrm{CS}$ or $\mathrm{H}_{2}$ on RCT. As shown in Fig. 2, the plasma radioactivity percentages of the total injection did not differ significantly from each other at each time point (Fig. 2a). Nevertheless, the liver radioactivity percentage of the total injection in the CS group was significantly decreased by $17 \%$ compared with the control group $(p<0.05)$, while the percentage in the $\mathrm{H}_{2}+\mathrm{CS}$ group was significantly increased by $21 \%$ compared with the CS group $(p<0.05)$ (Fig. 2b). In addition, the bile radioactivity percentage in the CS group was decreased by $35 \%$ compared with the control group, while the percentage in the $\mathrm{CS}+\mathrm{H}_{2}$ group was significantly increased by $72 \%$ compared with the CS group $(p<0.05)$

Table 2 Mice body weight comparisons

\begin{tabular}{lllll}
\hline Groups & Week0 & week8 & Week12 & $P$ value \\
\hline Control & $28.1 \pm 0.81$ & $29.5 \pm 1.01$ & $31.0 \pm 1.81$ & \\
$\mathrm{H}_{2}$ & $27.5 \pm 0.16$ & $28.4 \pm 0.37$ & $29.6 \pm 0.81$ & $0.108^{*}$ \\
$\mathrm{CS}$ & $28.1 \pm 0.47$ & $28.9 \pm 1.24$ & $30.1 \pm 0.93$ & $0.344^{*}$ \\
$\mathrm{H}_{2}+\mathrm{CS}$ & $29.1 \pm 0.63$ & $29.6 \pm 0.61$ & $30.3 . \pm 1.39$ & $0.819^{\#}$ \\
\hline
\end{tabular}

The $p$-values are calculated from the body weight data between different groups at week12. Values were indicated as means \pm S.D. $(n=18) .{ }^{*}$ Compared with the control group; \#: Compared with the CS group
(Fig. 2c). Moreover, the fecal radioactivity percentage in the CS group was significantly decreased by $48 \%$ compared with the control group $(p<0.05)$, while the percentage in the $\mathrm{CS}+\mathrm{H}_{2}$ group was significantly increased by $89 \%$ compared with the CS group $(p<0.05)$ (Fig. $2 d)$.

\section{CS exposure impairs HDL functionalities which can be minimized by $\mathrm{H}_{2}$ treatment}

Of all the functionalities, HDL's protection against LDL oxidation and the functionality to promote cholesterol efflux from peripheral macrophages are very important for RCT pathway. Therefore, we firstly determined plasma TBARS and found that CS exposure significantly increased TBARS formation by $64 \%$ compared with the control group, while $\mathrm{H}_{2}$ treatment significantly decreased by 53 \% compared with the CS group (Fig. 3a). We also determined plasma superoxide dismutase (SOD) levels by Enzyme-linked immunosorbent assay, but did not find any remarkable alterations (Fig. 3b). When determining the HDL's functionality to elicit the cholesterol efflux from $\left[{ }^{3} \mathrm{H}\right]$-cholesterol-laden macrophages in vitro, in the presence of cAMP in cell culture medium, we found that CS exposure significantly decreased the efflux by $26 \%$ compared with the control group $(p<0.05)$, while $\mathrm{H}_{2}$ treatment also significantly facilitated it by $32 \%$ compared with the CS group ( $p<$ 0.05) (Fig. 3c).

\section{Neither $\mathrm{H}_{2}$ treatment nor CS exposure significantly alters the expressions of RCT related genes}

To exclude other possibilities of the underlying molecular mechanisms of $\mathrm{H}_{2}$ or CS effect on $\mathrm{RCT}$, the expressions of key cholesterol transporters and cholesterol metabolic enzymes from hepatocytes or peritoneal macrophages were measured by real-time PCR or Western blot. As shown in Fig. 4, although $\mathrm{H}_{2}+\mathrm{CS}$ treatment significantly up-regulated the mRNA expressions of CYP7A1 and ABCG5 by $294 \%$ and $164 \%$, respectively, compared with the CS group (Fig. 4a), but neither $\mathrm{H}_{2}$ treatment nor CS exposure significantly altered the hepatic protein expressions of CYP7A1, ABCG5, LDLR and SRBI compared with the CS group or the control group (Fig. 4b-e). Besides, when determining the expressions of the cholesterol transporters from peritoneal macrophages, we also found that neither $\mathrm{H}_{2}$ treatment nor CS exposure significantly altered the protein expressions of $\mathrm{ABCA} 1$ and ABCG1 compared with the CS group or control group by Western blot (Fig. 4f-g).

\section{Discussion}

Cigarette smoking releases a complex mixture of more than 4,700 chemical constituents [20], including aldehydes which are risky constituents for atherosclerosis development. Freeman et al. reported that aldehydes 


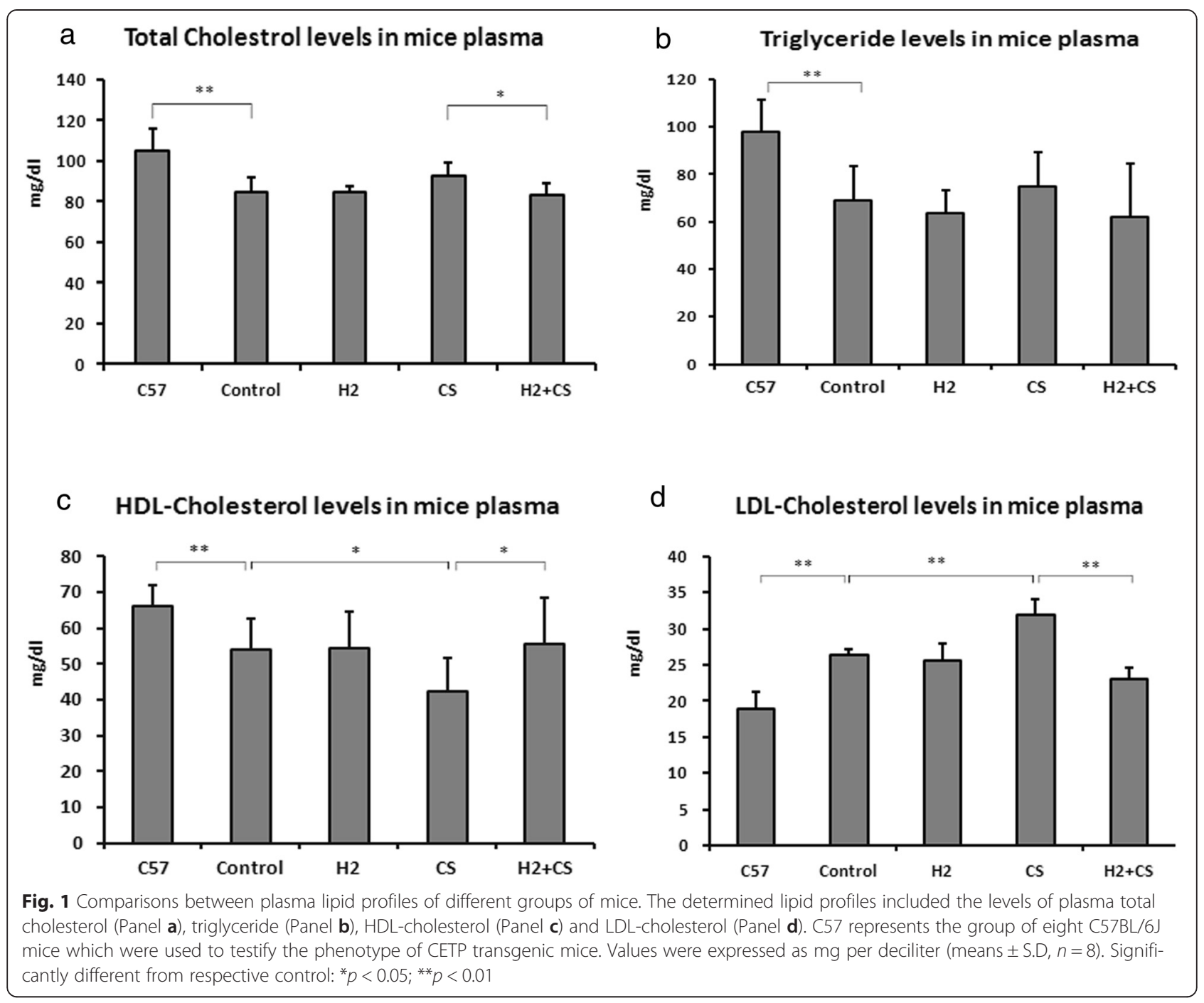

from CS react with lysine residues of lipoproteins, giving rise to adducted molecules in the presence of MDA [10]. Additionally, studies revealed that human and rat cigarette smokers accumulate more macrophages in developing lesions of thoracic and abdominal aortas than nonsmokers [21, 22].

Evidence in a variety of biomedical fields has proved that $\mathrm{H}_{2}$ acts as a feasible therapeutic strategy in different disease models [23-25]. Ohsawa et al. reported that oral consumption of $\mathrm{H}_{2}$ rich water prevented atherosclerosis in apoE-knockout mice fed a chow diet, primarily through decreasing the oxidative stress level in vivo $[23,26]$. Our previous studies in animal models and metabolic syndrome volunteers demonstrated that $\mathrm{H}_{2}$ supplementation decreased aortic atherosclerosis [12], reduced oxidative stress, improved hyperlipidemia-injured HDL functionality to stimulate macrophage cholesterol efflux $[13,14]$.

Consistent with previous studies $[9,27,28]$, the current study demonstrated that CS exposure could impair the plasma lipid profiles. Interestingly, we also found that $\mathrm{H}_{2}$ treatment significantly improved the levels of plasma HDL-C, LDL-C and TC compared with the CS group. These results recommended us that $\mathrm{CS}$ exposure or $\mathrm{H}_{2}$ treatment might alter the levels of plasma lipids through affecting apolipoprotein structures or enzyme activities on apolipoproteins. Considering that $\mathrm{H}_{2}$ helps to reduce oxidation stress [12-14], we proposed that $\mathrm{H}_{2}$ prevents certain CS constituents, such as aldehydes, from reacting with apolipoproteins and impairing their functionalities [10]. In other words, before $\mathrm{H}_{2}$ treatment CS exposure might impair apolipoproteins on HDL and (V) LDL particles, thus preventing cholesterol uptake from peripheral macrophages to HDL particles and the hepatic cholesterol transfer from (V) LDL particles to hepatocytes via hepatic LDLR or SRBI, leading to a significantly lowered level of HDL-C and increased levels of TC and LDL-C. Whereas, after $\mathrm{H}_{2}$ treatment this antioxidant significantly minimized the impairment of plasma lipid profiles, the metabolism of 
a

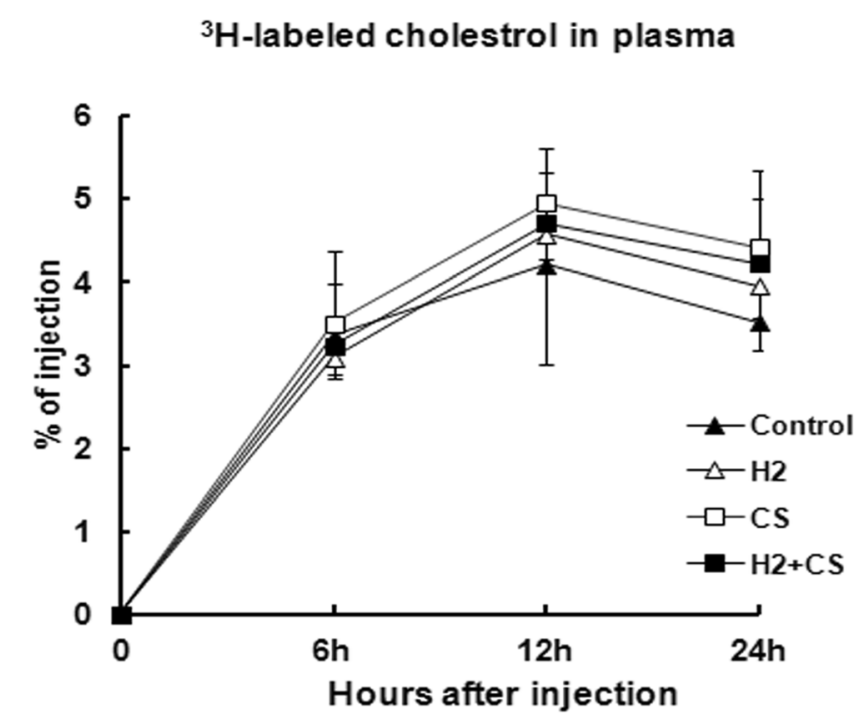

C

${ }^{3} \mathrm{H}$-labeled cholestrol in bile

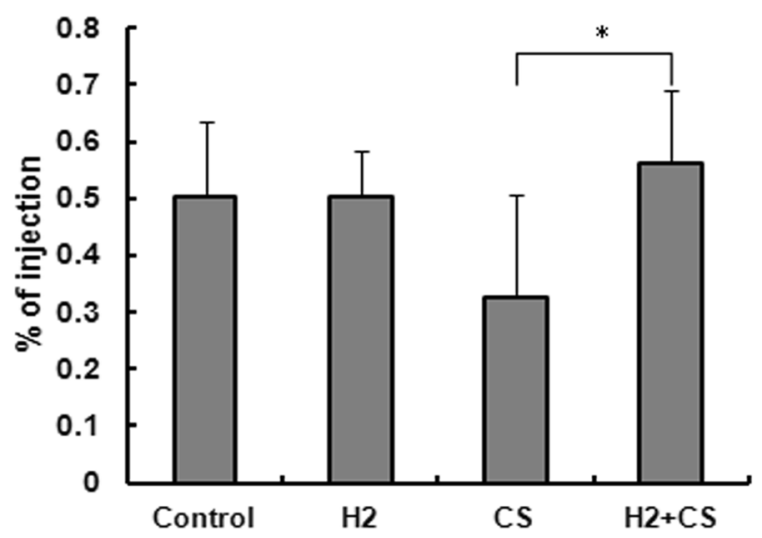

b

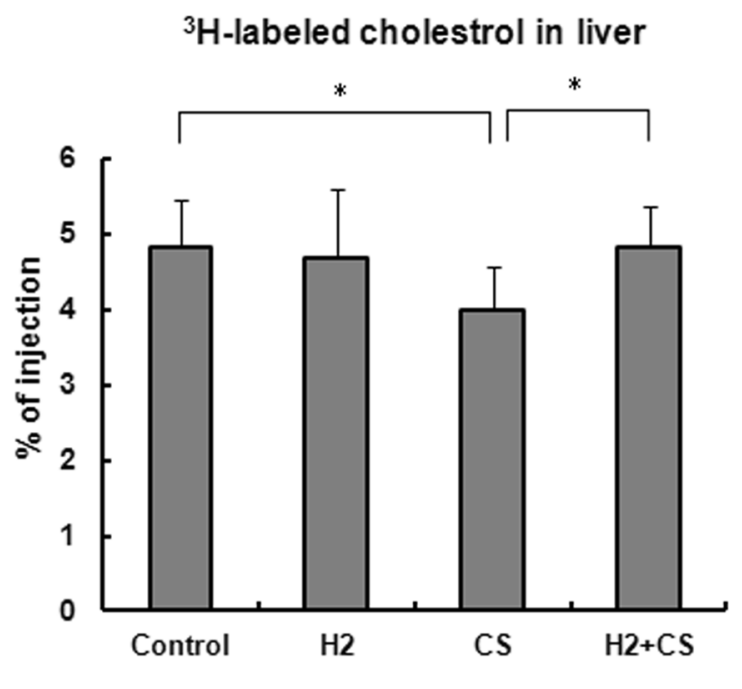

d

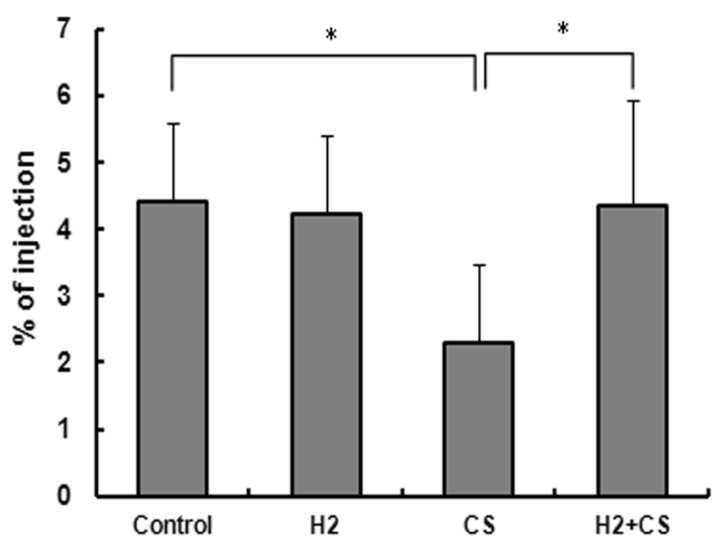

Fig. 2 Macrophage-to-feces RCT assay in CETP transgenic mice. Plasma, bile, liver tissue, and feces was isolated or collected for radioactivity determination. At 0, 6,12 and $24 \mathrm{~h}$ after injection, blood samples from each group were collected from the retro-orbital sinus for radioactivity determination (Panel a). The levels of $3 \mathrm{H}$-labeled cholesterol in liver (Panel $\mathbf{b}$ ), bile (Panel $\mathbf{c}$ ) and feces (Panel $\mathbf{d}$ ) from each group were also determined by liquid scintillation counting. Values were expressed as the percentages of the total injected radioactivity (means \pm S.D, $n=6$ for plasma, $n=9$ for liver, bile and feces). Significantly different from respective control: ${ }^{*} p<0.05$

which might be attributable to $\mathrm{H}_{2}$ antioxidation for CSimpaired apolipoproteins. Nevertheless, in view of the fact that $\mathrm{H}_{2}$ did not have any beneficial effects on nonsmokers in this study, $\mathrm{H}_{2}$ probably works as a potent antioxidant for oxidative stresses but has little beneficial effect on normal conditions.

The current study also demonstrated that CS exposure reduced the accumulation concentrations of $\left[{ }^{3} \mathrm{H}\right]$-tracer in liver, gallbladder bile and feces compared with the control group (Fig. 2). In addition, CS exposure not only increased the plasma MDA level but also impaired the functionality of HDL to elicit macrophage cholesterol efflux (Fig. 3). Whereas, nearly all these CS impairments could be minimize by $\mathrm{H}_{2}$ treatment. Then, what could be the most possible underlying mechanism for the impaired RCT pathway in the present study? And what is the role of $\mathrm{H}_{2}$ throughout the whole impairment of CS?

As is well known, normal plasma HDL helps to decrease the risk of atherosclerotic cardiovascular disease. However, as a result of oxidative stress, HDL 


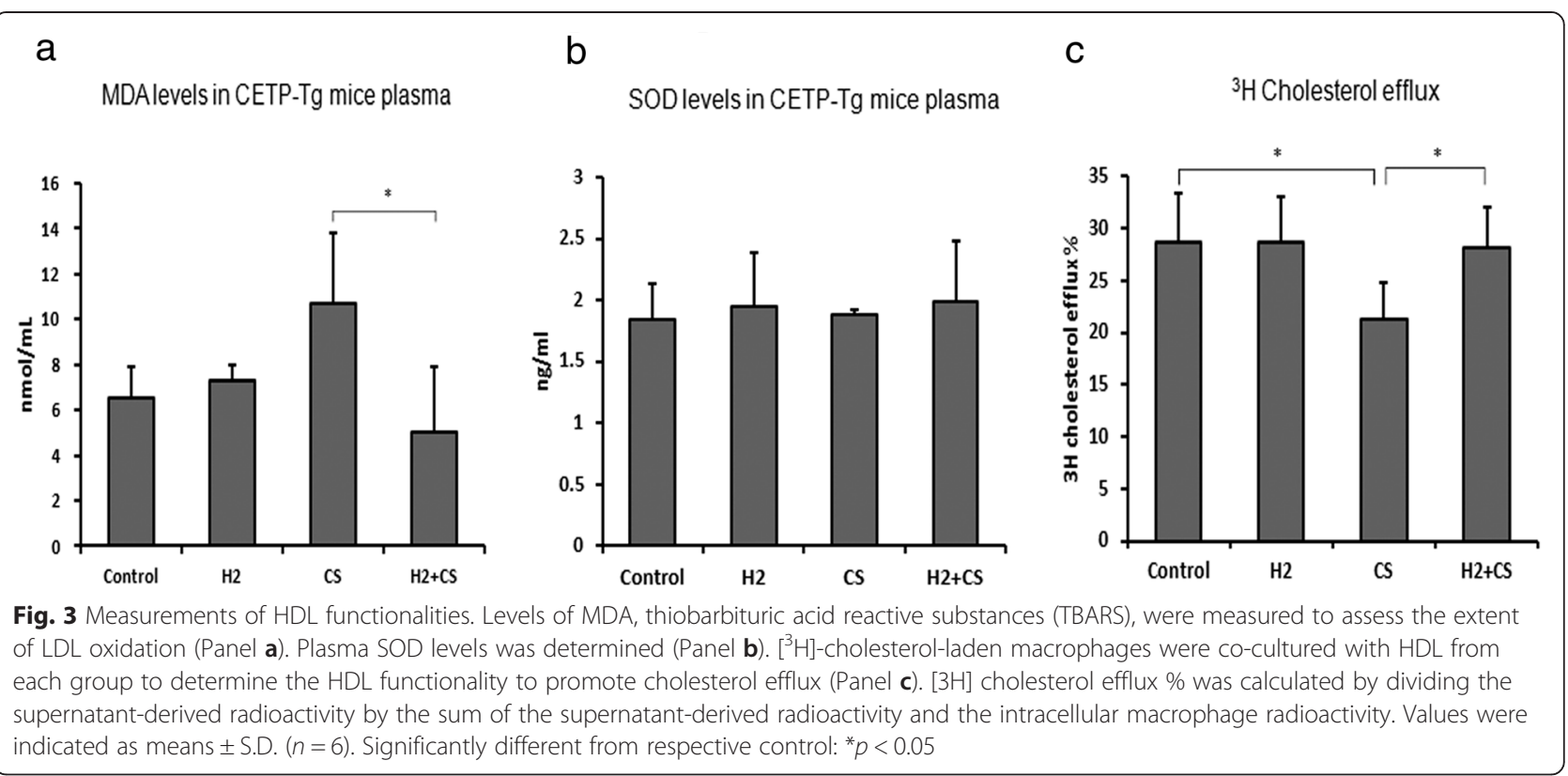

particles may undergo dramatic alterations in structure or composition, losing normal biological activities progressively $[29,30]$. Such HDL particles cannot protect LDL against oxidation, instead, they turn out to be a kind of dysfunctional HDL and play a proatherogenic role in RCT pathway [30]. McCall et al. also reported that CS exposure could induce a cross-linking of apolipoprotein A1 [31], giving rise to HDL conformational alteration $[10,32]$. Besides, the oxidative stress caused by CS exposure has been thought to be associated with plasma antioxidant depletion [33]. It was also reported that volunteer smokers' plasma MDA levels, a biomarker most frequently used to measure oxidative stress, were enhanced significantly compared with nonsmokers [34]. Therefore, in the present study it was very likely that CS constituents, such as aldehydes, reacted with MDA to form adducts on HDL particles [10], impairing their functionalities and the subsequent RCT pathway. Based on these, it might be concluded that CS constituents impair HDL functionality to stimulate cholesterol efflux and its property to protect against LDL oxidation, and that $\mathrm{H}_{2}$ probably helps to prevent MDA to react with lysines of apolipoproteins [10] on HDL particles, thus keeping the HDL functionalities intact upon CS exposure.

Although CS-impaired HDL might uptake less cholesterol from peripheral macrophages, leading to the impairment of lipid profiles, the expressions of key cholesterol transporters and enzymes in hepatocytes or peritoneal macrophages also contribute the lowered or increased levels of plasma HDL-C, TC and LDL-C. To exclude this possibility, we investigated the possible molecular mechanisms for our results (Fig. 4). CYP7A1, the primary ratelimited enzyme in the synthesis of bile acid, is responsible for the main consumption of liver cholesterol. The secretion of bile acid is mediated by ABCG5. LDL Receptors (LDLR) expressed in hepatocytes bind with apolipoprotein $\mathrm{E}$ or $\mathrm{B}$, and promote the uptake of cholesterol-containing (V) LDL in hepatocytes. Both ABCA1 or ABCG1 expressed in peripheral macrophages mediates cholesterol efflux to lipid-poor apolipoproteins or mature HDL, respectively. However, as shown in Fig. 4, we did not find that any significant alterations of the expressions of CYP7A1, ABCG5, SRB1, LDLR ABC-A1 or ABC-G1 expressed in hepatocytes or peritoneal macrophages. Thus, we might conclude that the effects of CS exposure on RCT and the antioxidative effects of $\mathrm{H}_{2}$ treatment against CS exposure are primarily through impairing or improving the functionalities of $\mathrm{HDL}$, rather than enhancing the protein expressions of cholesterol transporters and cholesterol metabolic enzymes along RCT pathway.

Nevertheless, this study has a list of limitations. Firstly, to further characterize the inner action mechanism of $\mathrm{H}_{2}$ on CS-impaired HDL particles, tandem mass spectrometry should be used to elucidate what kinds of peroxide components on HDL particles had been derived from CS impairment and the mechanism of how $\mathrm{H}_{2}$ reacts with these derivatives. Secondly, it is well known that lipid-free apoA-I is the lipid acceptor for ABCA1-mediated cholesterol efflux [35-37], while SRBI [38] and ABCG1 [39, 40] are identified as mediators of cholesterol efflux to mature HDL. It remains to be further investigated which apolipproteins or cholesterol transporters should be responsible for the result of cholesterol efflux in this study. Thirdly, a lot of interventions of nutraceuticals have already been investigated on lipid disorders beyond pharmacological interventions [41]. The beneficial actions of nutraceuticals 


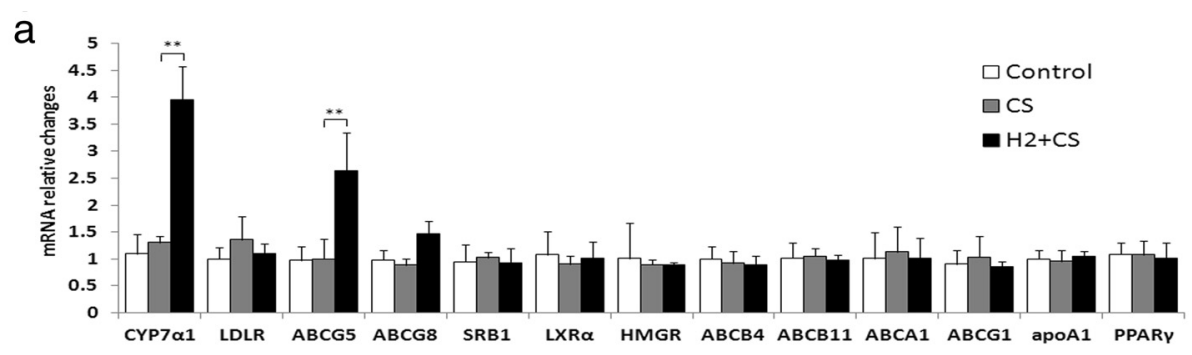

b
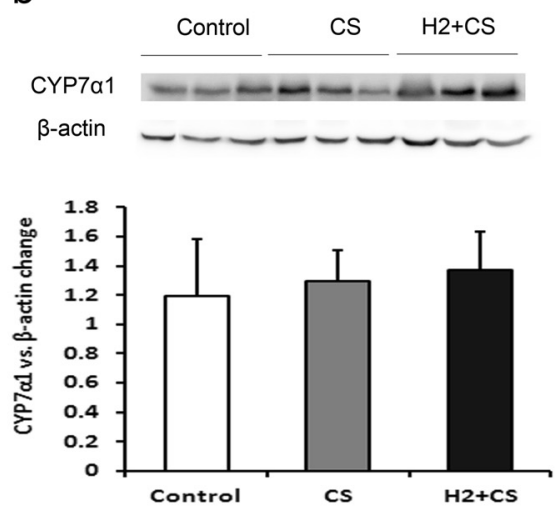

d
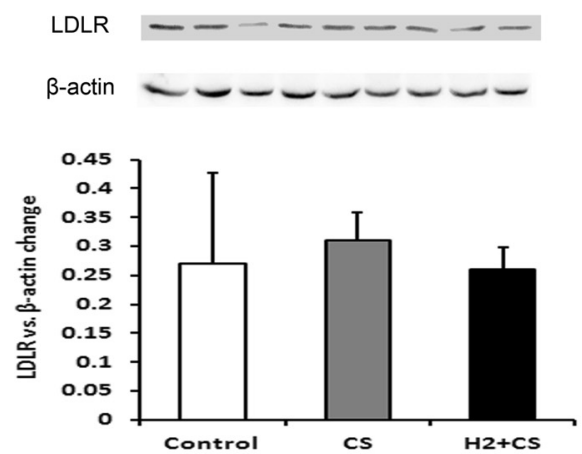

f
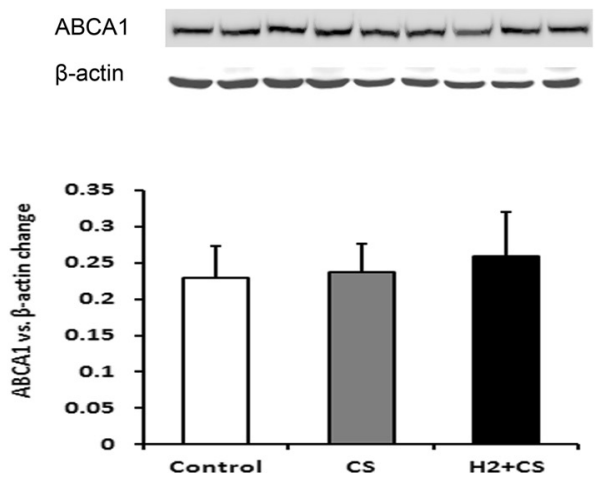

C
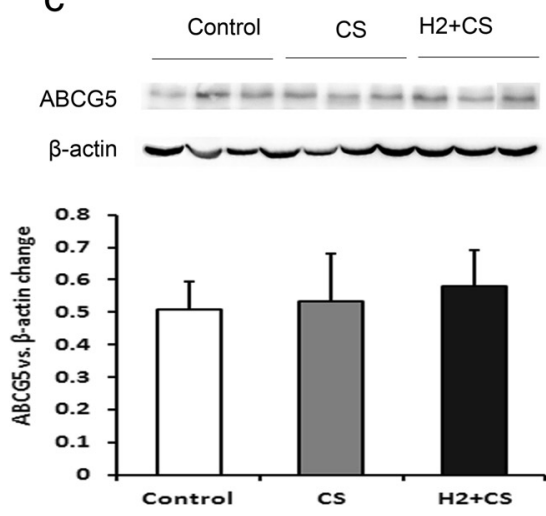

e
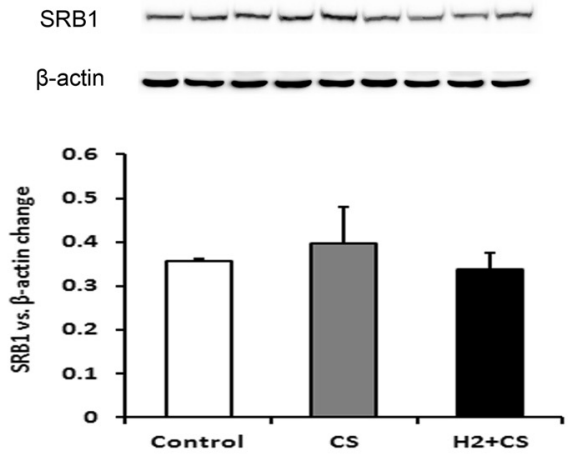

g
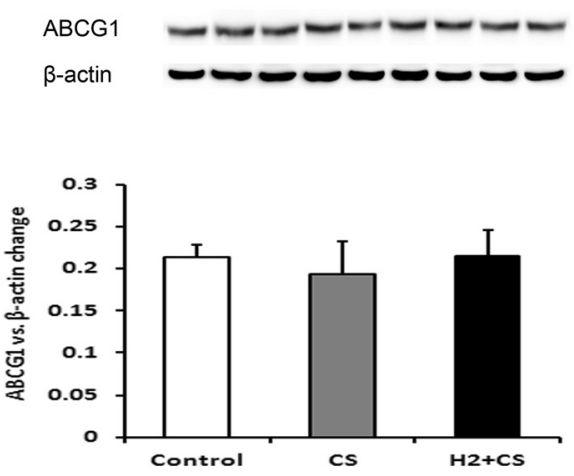

Fig. 4 (See legend on next page.) 
(See figure on previous page.)

Fig. 4 Hepatic expressions of the key cholesterol transporters or enzymes in RCT. mRNA expressions of hepatic cholesterol transporters or enzymes were measured by real-time PCR $(n=6)$ a. Values are indicated as relative expression changes compared with respective control. Hepatic protein expressions were measured by Western blots $\mathbf{b}-\mathbf{e}$. Peritoneal macrophages were also measured by Western blot $\mathbf{f}-\mathbf{g}$. Western blot results were shown on upper panels and their quantifications were shown on down panels. Values were indicated as mean \pm S.D. ( $n=5$ for CYP7A1 and ABCG5, $n=3$ for others). Significantly different from the CS group: ${ }^{*} p<0.01$

may be related to several mechanisms such as endothelial function amelioration [42], antithrombotic activities [43] and improving lipid metabolism mechanisms [44]. Unlike these nutraceuticals, in view of the fact that the problem for maintenance of $\mathrm{H}_{2}$ saturated concentration in cell culture medium has not been addressed, the action mechanism of $\mathrm{H}_{2}$ still remains poorly understood. Finally, although one of our previous studies demonstrated that supplementation with $\mathrm{H}_{2}$-rich water decreases serum LDL-C, improves dyslipidemia-injured HDL functionalities and reduces the oxidative stress, and concluded that $\mathrm{H}_{2}$ might have a beneficial role in prevention of metabolic syndrome [13], further $\mathrm{H}_{2}$ atheroprotective studies on humans should still be required to fully understand the mechanism of $\mathrm{H}_{2}$ beneficial effects on lipid disorders.

In conclusion, our findings suggested that CS exposure in vivo impairs the plasma lipid profiles, the HDL functionalities and the subsequent macrophage-to-feces RCT pathway in CETP transgenic mice, and that $\mathrm{H}_{2}$ treatment decreases plasma MDA level, thereby prevents apolipoproteins to react with MDA, and thus minimizes the CS-impaired RCT pathway.

\footnotetext{
Abbreviations

ABCA1/G1: ATP-binding cassette A1/G1; ABCG5: ATP-binding cassette G5; CETP: cholesteryl ester transfer protein; CS: cigarette smoke; CYP7A1: cholesterol 7 alpha-hydroxylase; $\mathrm{H}_{2}$ : hydrogen; $\mathrm{HDL}$ : high-density lipoprotein particles; HDL-C and LDL-C: high-density lipoprotein cholesterol and Low-density lipoprotein cholesterol; LDLR: LDL receptor; MDA: Malondialdehyde; RCT: reverse cholesterol transport; SRBI: scavenger receptor class B type I; TBARS: thiobarbituric acid reactive substances; TC and TG: total cholesterol and Total triglyceride.
}

\section{Competing interests}

The authors do not have any relevant affiliations or financial involvement with any entity with financial interest or conflict related to these studies.

\begin{abstract}
Authors' contributions
All authors participated in animal sacrifice, tissue collection, data analysis and review of the manuscript. CZ and ZG were responsible for acquisition of isotope tracing assay data. CZ and NY were responsible for animal maintenance, intraperitoneal injection, genetype screening and acquisition of body weight data. NY and ZG were responsible for acquisition of RNA and protein data. SY were responsible for acquisition of plasma lipid profile data and data analysis. CZ and GS was responsible for cigarette smoke exposure to animals. CZ, GS and SQ were responsible for study design, data analysis and manuscript preparation. CZ and GS contributed equally to this study. All authors read and approved the final manuscript.
\end{abstract}

\section{Acknowledgments}

The present study was supported by Shandong Provincial Natural Science Foundation, China (ZR2012HM034) for C Z, the Taishan Scholars Foundation of Shandong Province (200811) for S Q, the National Natural Science
Foundation of China (81200216) and the Promotive Research Fund for Excellent Young and Middle-aged Scientists of Shandong Province, China (BS2012YY034) for GS.

\section{Author details}

${ }^{1}$ Key Laboratory of Atherosclerosis in Universities of Shandong Province, Institute of Atherosclerosis, Taishan Medical University, 2\# Yingsheng East Road, Taian, Shandong 271000, PR China. ${ }^{2}$ School of Basic Medicine Sciences, Taishan Medical University, 2\# Yingsheng East Road, Taian, Shandong 271000, PR China.

Received: 10 October 2015 Accepted: 25 November 2015

Published online: 03 December 2015

\section{References}

1. Glomset JA. The plasma lecithins:cholesterol acyltransferase reaction. J Lipid Res. 1968;9:155-67.

2. Lewis GF, Rader DJ. New insights into the regulation of HDL metabolism and reverse cholesterol transport. Circ Res. 2005;96:1221-32.

3. Cuchel M, Rader DJ. Macrophage reverse cholesterol transport: key to the regression of atherosclerosis? Circulation. 2006;113:2548-55.

4. Agellon LB, Walsh A, Hayek T, Moulin P, Jiang XC, Shelanski SA, et al. Reduced high density lipoprotein cholesterol in human cholesteryl ester transfer protein transgenic mice. J Biol Chem. 1991;266:10796-801.

5. Hesler CB, Tall AR, Swenson TL, Weech PK, Marcel YL, Milne RW. Monoclonal antibodies to the $\mathrm{Mr} 74,000$ cholesteryl ester transfer protein neutralize all of the cholesteryl ester and triglyceride transfer activities in human plasma. J Biol Chem. 1988;263:5020-3.

6. Dinchuk J, Hart J, Gonzalez G, Karmann G, Schmidt D, Wirak DO. Remodelling of lipoproteins in transgenic mice expressing human cholesteryl ester transfer protein. Biochim Biophys Acta. 1995;1255:301-10.

7. Craig WY, Palomaki GE, Haddow JE. Cigarette smoking and serum lipid and lipoprotein concentrations: an analysis of published data. BMJ. 1989:298:784-8.

8. Alonso M, Godayol A, Antico' E, Sanchez JM. Assessment of environmental tobacco smoke contamination in public premises: significance of 2,5dimethylfuran as an effective marker. Environ Sci Technol. 2010;44:8289-94.

9. Gokulakrisnan A, Jayachandran Dare B, Thirunavukkarasu C. Attenuation of the cardiac inflammatory changes and lipid anomalies by (-)-epigallocatechin-gallate in cigarette smoke-exposed rats. Mol Cell Biochem. 2011;354(1-2):1-10.

10. Freeman TL, Haver A, Duryee MJ, Tuma DJ, Klassen LW, Hamel FG, et al. Aldehydes in cigarette smoke react with the lipid peroxidation product malonaldehyde to form fluorescent proteinadducts on lysines. Chem Res Toxicol. 2005;18(5):817-24.

11. Nagano Y, Arai H, Kita T. High density lipoprotein loses its effect to stimulate efflux of cholesterol from foam cells after oxidative modification. Proc Natl Acad Sci. 1997:88:6457-61.

12. Song G, Tian H, Qin S, Sun X, Yao S, Zong C, et al. Hydrogen decreases athero-susceptibility in apolipoprotein B-containing lipoproteins and aorta of apolipoprotein E knockout mice. Atherosclerosis. 2012;221(1):55-65.

13. Song G, Li M, Sang H, Zhang L, Li X, Yao S, et al. Hydrogen-rich water decreases serum LDL-cholesterol levels and improves $\mathrm{HDL}$ function in patients with potential metabolic syndrome. J Lipid Res. 2013;54(7):1884-93.

14. Zong C, Song G, Yao S, Li L, Yu Y, Feng L, et al. Administration of hydrogensaturated saline decreases plasma low-density lipoprotein cholesterol levels and improves high-density lipoprotein function in high-fat diet-fed hamsters. Metabolism. 2012;61(6):794-800.

15. Miyazaki A, Sakai M, Suginohara Y, Hakamata H, Sakamoto Y, Morikawa W, et al. Acetylated low density lipoprotein reduces its ligand activity for the 
scavenger receptor after interaction with reconstituted high density lipoprotein. J Biol Chem. 1994;269(7):5264-9.

16. Escolar JD, Martinez MN, Rodriguez FJ, Gonzalo C, Escolar MA, Roche PA. Emphysema as a result of involuntary exposure to tobacco smoke: morphometrical study of the rat. Exp Lung Res. 1995;21:255-73.

17. Yu Y, Si Y, Song G, Luo T, Wang J, Qin S. Ethanolic Extract of Propolis Promotes Reverse Cholesterol Transport and the Expression of ATP-Binding Cassette Transporter A1 and G1 in Mice. Lipids. 2011:46(9):805-11.

18. Smith JD, Miyata M, Ginsberg M, Grigaux C, Shmookler E, Plump AS. Cyclic AMP induces apolipoprotein E binding activity and promotes cholesterol efflux from a macrophage cell line to apolipoprotein acceptors. J Biol Chem. 1996;271:30647-55.

19. Rikitake Y, Hirata K, Kawashima S, Akita H, Yokoyama M. Inhibitory effect of inducible type nitric oxide synthase on oxidative modification of low density lipoprotein by vascular smooth muscle cells. Atherosclerosis. 1998;136:51-7.

20. Smith CJ, Fischer TH. Particulate and vapor phase constituents of cigarette mainstream smoke and risk of myocardial infarction. Atherosclerosis. 2001; 158:257-67.

21. Botti TP, Amin H, Hiltscher L, Wissler RW. A comparison of the quantitation of macrophage foam cell populations and the extent of apolipoprotein $E$ deposition in developing atherosclerotic lesions in young people: high and low serum thiocyanate groups as an indication of smoking. PDAY Research Group. Pathobiological Determinants of Atherosclerosis in Youth. Atherosclerosis. 1996;124:191-202.

22. Bazin M, Turcotte $H$, Lagace $\mathrm{R}$, Boutet $\mathrm{M}$. Cardiovascular effects of cigarette smoke in the rat. Aortic endothelial and myocardial capillary permeability in the rat. Rev Can Biol. 1981;40:263-76.

23. Ohsawa I, Ishikawa M, Takahashi K, Watanabe M, Nishimaki K, Yamagata K, et al. Hydrogen acts as a therapeutic antioxidant by selectively reducing cytotoxic oxygen radicals. Nat Med. 2007;13:688-94.

24. Kajiyama S, Hasegawa G, Asano M, Hosoda H, Fukui M, Nakamura N, et al. Supplementation of hydrogen-rich water improves lipid and glucose metabolism in patients with type 2 diabetes or impaired glucose tolerance. Nutr Res. 2008;28:137-43.

25. Suzuki Y, Sano M, Hayashida K, Ohsawa I, Ohta S, Fukuda K. Are the effects of alpha-glucosidase inhibitors on cardiovascular events related to elevated levels of hydrogen gas in the gastrointestinal tract. FEBS Lett. 2009;583:2157-9.

26. Ohsawa I, Nishimaki K, Yamagata K, Ishikawa M, Ohta S. Consumption of hydrogen water prevents atherosclerosis in apolipoprotein E knockout mice. Biochem Biophys Res Commun. 2008;377:1195-8.

27. Hodhod MA, Hamdy AM, Ahmed MB, Youssef SR, Aly SM. Effect of passive smoking on blood lymphocyte apoptosis in children. Eur J Clin Invest. 2011; 41(4):387-92.

28. Damasceno DC, Sinzato YK, Bueno A, Dallaqua B, Lima PH, Calderon IM, et al. Metabolic profile and genotoxicity in obese rats exposed to cigarette smoke. Obesity (Silver Spring). 2013;21(8):1596-601.

29. Esteve E, Ricart W, Fernandez-Real JM. Dyslipidemia and inflammation: an evolutionary conserved mechanism. Clin Nutr. 2005;24:16-31.

30. Van Lenten BJ, Navab M, Shih D, Fogelman AM, Lusis AJ. The role of highdensity lipoproteins in oxidation and inflammation. Trends Cardiovasc Med. 2001;11(3-4):155-61.

31. McCall MR, van den Berg JJM, Kuypers FA, Tribble DL, Krauss RM, Knoff LJ, et al. Modification of LCAT activity and HDL structure: new links between cigarette smoke and CHD risk. Arterioscler Thromb. 1994;14:248-53.

32. Bielicki JK, McCall MR, van den Berg JJM, Kuypers FA, Forte TM. Copper and gas-phase cigarette smoke inhibit plasma 1ecithin:cholesterol acyltransferase activity by different mechanisms. J Lipid Res. 1995;36:322-31.

33. Marangon K, Herbeth B, Lecomte E, Paul-Dauphin A, Grolier P, Chancerelle Y, et al. Diet, antioxidant status, and smoking habits in French men. Am J Clin Nutr. 1998;67:231-9.

34. Karvonen J, Kauma H, Kervinen K, Ukkola O, Rantala M, Päivänsalo M, et al. Apolipoprotein E polymorphism affects carotid artery atherosclerosis in smoking hypertensive men. J Hypertens. 2002;20:2371-8.

35. Wang N, Silver DL, Costet $P$, Tall AR. Specific binding of ApoA-I, enhanced cholesterol efflux, and altered plasma membrane morphology in cells expressing ABC1. J Biol Chem. 2000;275:33053-8.

36. Oram JF, Lawn RM, Garvin MR, Wade DP. ABCA1 is the CAMP-inducible apolipoprotein receptor that mediates cholesterol secretion from macrophages. J Biol Chem. 2000;275:34508-11.
37. Bortnick AE, Rothblat GH, Stoudt G, Hoppe KL, Royer $L$, McNeish J, et al. The correlation of ATP-binding cassette 1 mRNA levels with cholesterol efflux from various cell lines. J Biol Chem. 2000;275:28634-40.

38. Yancey PG, de la Llera-Moya M, Swarnakar S, Monzo P, Klein SM, Connelly MA et al. High density lipoprotein phospholipid composition is a major determinant of the bi-directional flux and net movement of cellular free cholesterol mediated by scavenger receptor BI. J Biol Chem. 2000;275:36596-604.

39. Wang N, Lan D, Chen W, Matsuura F, Tall AR. ATP-binding cassette transporters G1 and G4 mediate cellular cholesterol efflux to high-density lipoproteins. Proc Natl Acad Sci. 2004;101:9774-9.

40. Kennedy MA, Barrera GC, Nakamura K, Baldan A, Tarr P, Fishbein MC, et al. ABCG1 has a critical role in mediating cholesterol efflux to $\mathrm{HDL}$ and preventing cellular lipid accumulation. Cell Metab. 2005;1:121-31.

41. Pietro S, Matteo C, Maria M. Nutraceuticals and dyslipidaemia: Beyond the common therapeutics. Journal of Functional Foods. 2014;6:11-32.

42. Zuchi C, Ambrosio G, Luscher TF, Landmesser U. Nutraceuticals in cardiovascular prevention: Lessons from studies on endothelial function. Cardiovasc Ther. 2010;28:187-201. 202-215.

43. Chakrabarti S, Freedman JE. Review: Nutriceuticals as antithrombotic agents. Cardiovasc Ther. 2010;28:227-35.

44. Rahimi-Ardabili B, Argani H, Ghorbanihaghjo A, Rashtchizadeh N, NaghaviBehzad M, Ghorashi S, et al. Paraoxonase enzyme activity is enhanced by zinc supplementation in hemodialysis patients. Ren Fail. 2012;34:1123-8.

\section{Submit your next manuscript to BioMed Central and we will help you at every step:}

- We accept pre-submission inquiries

- Our selector tool helps you to find the most relevant journal

- We provide round the clock customer support

- Convenient online submission

- Thorough peer review

- Inclusion in PubMed and all major indexing services

- Maximum visibility for your research

Submit your manuscript at www.biomedcentral.com/submit

C Biomed Central 